\title{
Amelogenesis imperfecta and the treatment plan - interdisciplinary team approach
}

\author{
Suchancova $\mathrm{B}^{1}$, Holly $\mathrm{D}^{1}$, Janska $\mathrm{M}^{1}$, Stebel $\mathrm{J}^{1}$, Lysy $\mathrm{J}^{1}$, Thurzo $\mathrm{A}^{1}$, Sasinek $\mathrm{S}^{2}$ \\ Department of Dentistry and Maxillofacial Surgery, Comenius University, St. Elisabeth's Hospital, Bratislava, \\ Slovakia.blanka.suchancova@gmail.com
}

\begin{abstract}
Amelogenesis imperfecta is a set of hereditary defects representing mainly the development defects of enamel without the presence of whole-body symptoms. Developmental disorders can manifest a complete absence of enamel, which is caused by improper differentiation of ameloblasts. This article describes the diagnosis and treatment of a patient with amelogenesis imperfecta, as well as the need for interdisciplinary cooperation to achieve the best possible morphological, skeletal, functional and aesthetic rehabilitation of the patients with this diagnosis. Furthermore, the article reviews literature dealing with other anomalies occurring in association with amelogenesis imperfect (Fig. 12, Ref. 20). Text in PDF www.elis.sk.

Key words: amelogenesis imperfecta, interdisciplinary cooperation, orthodontic treatment, disturbance of teeth development.
\end{abstract}

Developmental disorder of the dental enamel - amelogenesis imperfecta (AI) may occur in different stages, from hypomineralization through hypocalcification to hypomaturation of enamel. According to scientific studies it is related to a genetic predisposition and it may show autosomal dominant, autosomal recessive, or X-gene linked inheritance patterns. In cases with an X-linked form, the disorder may result from a mutation in the amelogenin gene, AMELX. In cases of dominant forms of AI, the enamelin gene, ENAM, is implicated in the pathogenesis $(1,13,14,15)$.

In certain forms of AI, an increased incidence of carries, late teeth eruption, or even teeth retention is reported. This could be occasionally associated with gingivitis and increased tartar deposition $(10,11)$.

AI can affect deciduous as well as permanent dentition, and requires a specific preventive and restorative care. This condition often presents as microdontia, teeth are discoloured, adopt a specific shape, and are widely spaced especially in the frontal area. As the defective enamel is very thin or even completely absent, the yellowish or brown dentin of the crown is revealed and the teeth are very sensitive. Apart from functional problems, this condition also brings appearance-related psychological problems, and at the important time in social development, children may become target of ridicule from their peers.

Treatment of the condition is aimed at restoring the proper function and preventing the thermal sensitivity of teeth. The final phase of the treatment should fulfil emotional and aesthetic demands so that the young patient can gain social self-confidence.

${ }^{1}$ Department of Dentistry and Maxillofacial Surgery, Comenius University, St. Elisabeth's Hospital, Bratislava, Slovakia, and 'Zirkonzahn, Dental Laboratory, Bratislava, Slovakia

Address for correspondence: B. Suchancova, MD, Department of Dentistry and Maxillofacial surgery, Comenius University, St. Elisabeth's Hospital, Heydukova 10, SK-812 50 Bratislava, Slovakia.
Treatment management of AI requires a supportive multidisciplinary approach. In addition to teeth defect, also hypercementosis, root malformation, anomalies in teeth position, or even skeletal deviation may occur $(16,17)$. In these cases an orthodontic treatment should precede the definitive prosthodontic or surgical treatment. An appropriate hygiene is essential as gingival inflammation and bleeding do not allow sufficient conservative and prosthodontic treatment.

Many patients affected by AI have the additional signs of skeletal changes often in association with open bite. Recent studies indicate that the incidence of open bite is higher in boys compared to girls $(16,17)$.

Classification system of AI describes more than ten subtypes. However, based on enamel appearance, there are four classes of AI, namely hypoplastic (type I), hypomature (type II), hypocalcified (type III) or combined hypomaturation-hypoplastic (type IV) (12).

Dental enamel is a highly mineralized tissue with over $95 \%$ of its volume being occupied by large highly organized hydroxyapatite crystals (12). A defect can occur at various stages of enamel formation.

Hypoplastic type I is the type of AI developed at the stage of enamel formation, in which the enamel does not mature to its normal thickness. The characteristic clinical features are those of teeth with discolouration and surface irregularities caused by hypoplastic areas on the normally hard enamel surface. The enamel is well mineralized but its amount is reduced.

Hypomature type II occurs in association with abnormal mineralization process in final stages of enamel maturation and thus results in defective development and growth of enamel crystallites. The width of enamel is normal but the texture is softer and tends to chip off from the underlying dentin. 


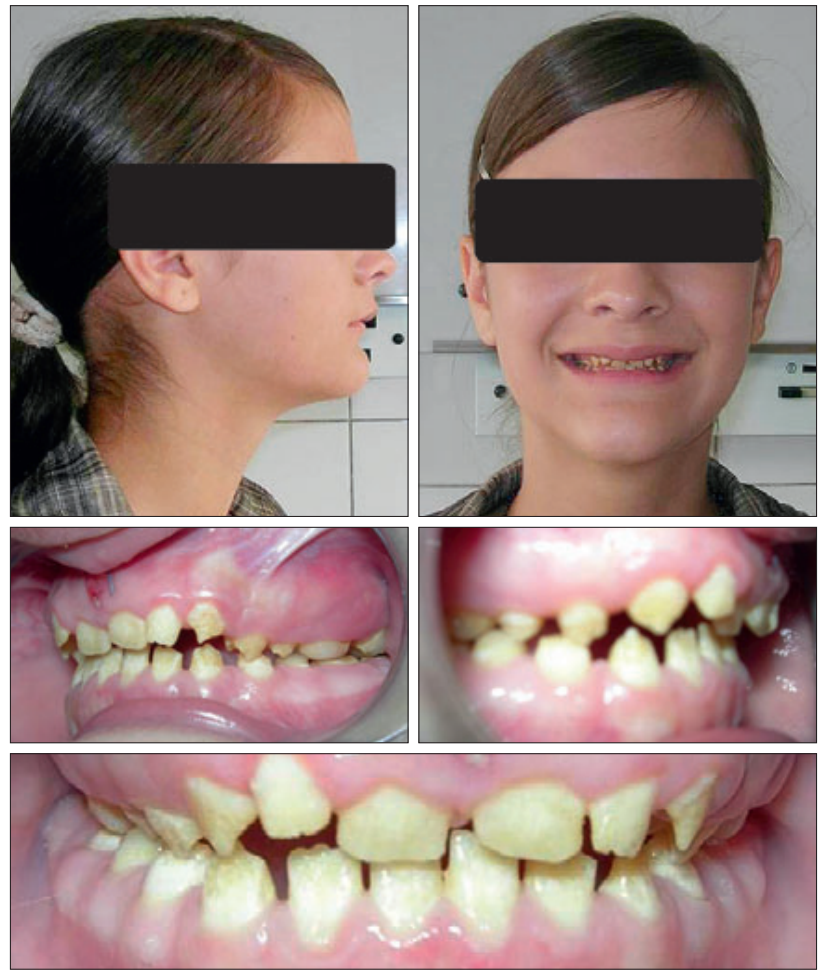

Fig. 1. Patient before treatment.

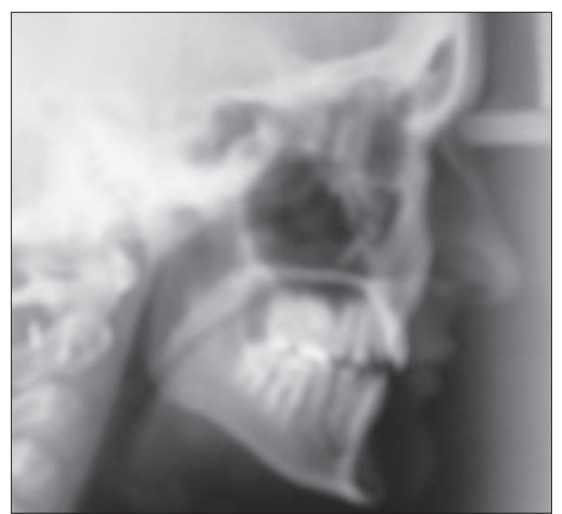

Fig. 1a. Tele $\mathrm{X}$-ray before treatment.

The defective calcification leads to demineralization of enamel and hypocalcified type III of AI. The enamel's thickness of the newly erupted teeth is normal but the enamel is soft, friable, and upon mechanical pressure, it can easily be removed from dentin. The whole tooth is then built only of dentin. The involved teeth are yellowish-brown in colour and their dentin tubules are obliterated due to the reaction of dentin-pulp complex $(2,3,9)$.

The treatment of amelogenesis imperfecta requires an interdisciplinary long-term approach, possibly lasting a few years. The treatment plan relies on the type of defect and its possible association with teeth position or jaw malocclusion (18).

First, all decayed teeth must be restored. In many cases, temporary protective crowns could be placed on the first erupted per-

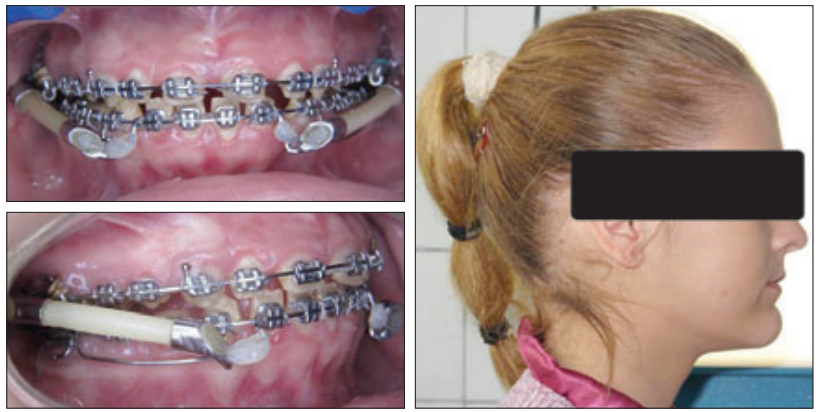

Fig. 2. Fixed appliance and flex developer in situ, patient's profile with sagital improvement.

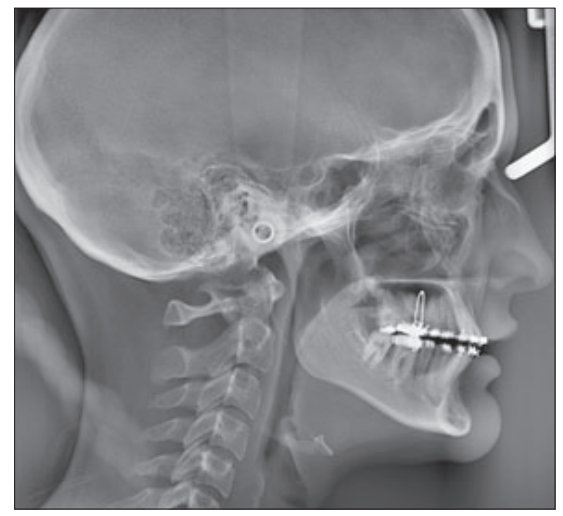

Fig. 2a. Tele $\mathrm{X}$-ray with sagital improvement during treatment.
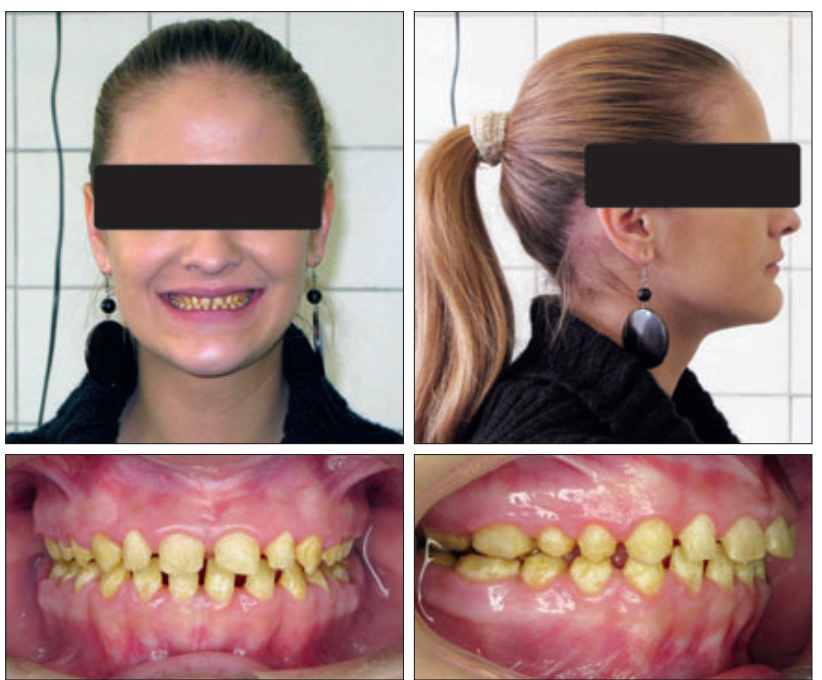

Fig. 3. Patient after the orthodontic treatment.

manent teeth. In the past, golden crowns were used; today there are more aesthetic possibilities, as for example Cristobal (Dentsply Ceramco). The definitive aesthetic restoration is achieved by metalfree zirconia crowns or metal ceramic crowns. For example, Captek crowns require minimal preparation and accomplish excellently aesthetic appearance. They have a golden matrix composed of gold $(97.5 \%)$ and palladium/platinum $(2.5 \%)(19,20)$. 


\section{Case report}

A 14-year old female patient presented with severe hypocalcified type III of amelogenesis imperfecta. She came for an orthodontic treatment before her final prosthodontic therapy. Apart from an extreme sensitivity to hot and cold, the patient's chief complaint was dissatisfaction with the appearance of her teeth.
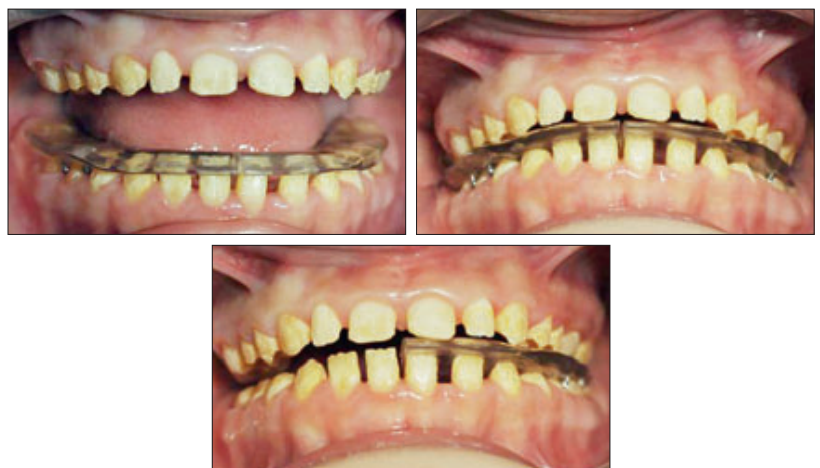

Fig. 4. Status with hard resin splint in situ.
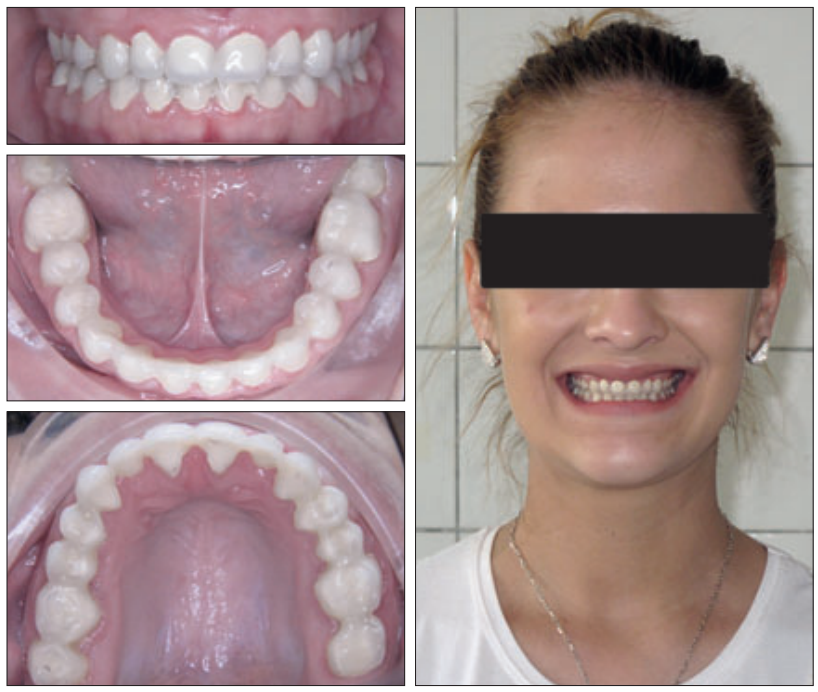

Fig. 5. Status with provisional prosthodontics.
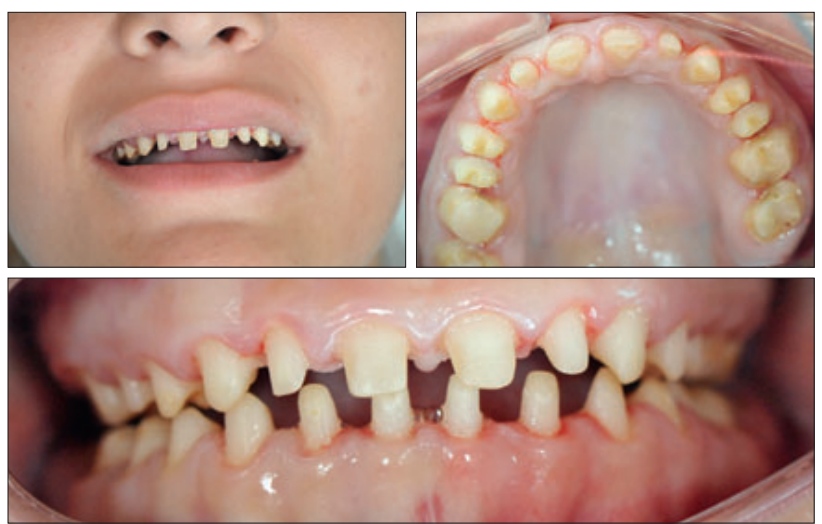

Fig. 6. Preparation of teeth before definitive reconstruction.

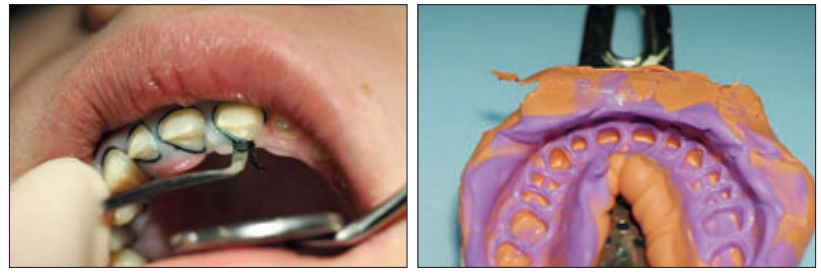

Fig. 7. Dental impressions.

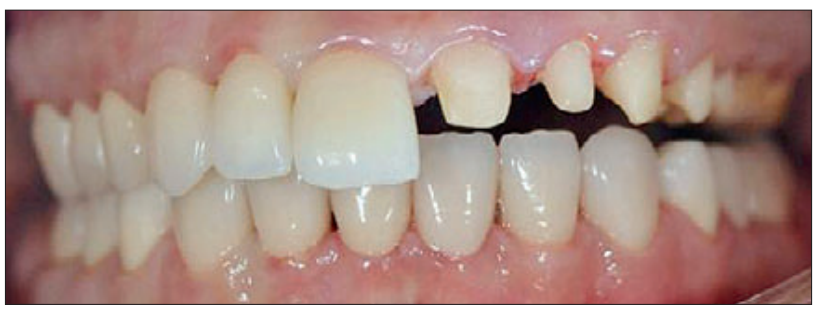

Fig. 8. Comparison of the treated right side with the left side before crown cementing to show the height of new crowns.

Detailed dental, medical, and social aspects of history were obtained from the patient. Clinical examination of the patient revealed a skeletal malocclusion. Radiographic analysis showed retrooclusion with retrusion of the upper frontal teeth associated with a mild maxillary constriction and open bite. This kind of teeth position requires orthodontic pre-treatment without which the final crowns cannot be properly made. The retrooclusion also negatively influences the patient's profile appearance (Figs 1 and 1a).

Owing to the patient's young age, it was possible to use the orthodontic treatment also for the correction of skeletal malocclusion.

The treatment plan was as follows:

Following a complex examination and preparation of detailed treatment plan, the orthodontic treatment commenced with placing the fixed appliances directly on the patient's teeth.

Due to defective enamel, a special glass-ionomer cement Dyract was used for adhesion of orthodontic brackets. Well-aligned arches were obtained after using novelisation wires. After this, a $0.017 \times 0.025$-inch stainless steel wire fixation and lingual transpalatal arch were inserted. For correction of the skeletal malocclusion, a jumping appliance referred to as flex-developer was placed. This appliance had to be permanently used for 6-9 months with regular activation in sagital direction. This leads to improvement of the patient's profile (Figs 2 and 2a).

Furthermore, the fixed appliance corrects the position of the teeth with maintaining equal gaps among them to enable enough space for the definitive treatment by ceramic crowns. The orthodontic treatment of our patient lasted 3 years. After removing the fixed appliances (Fig. 3) the definitive prosthodontic treatments followed.

First, definitive restoration with wider and longer ceramic crowns required a 2-mm increase in occlusion height. This was achieved by using a removable hard splint manufactured according to required measurements (Fig. 4). The patient wore it for 2 months. This was important for slow adaptation of temporoman- 


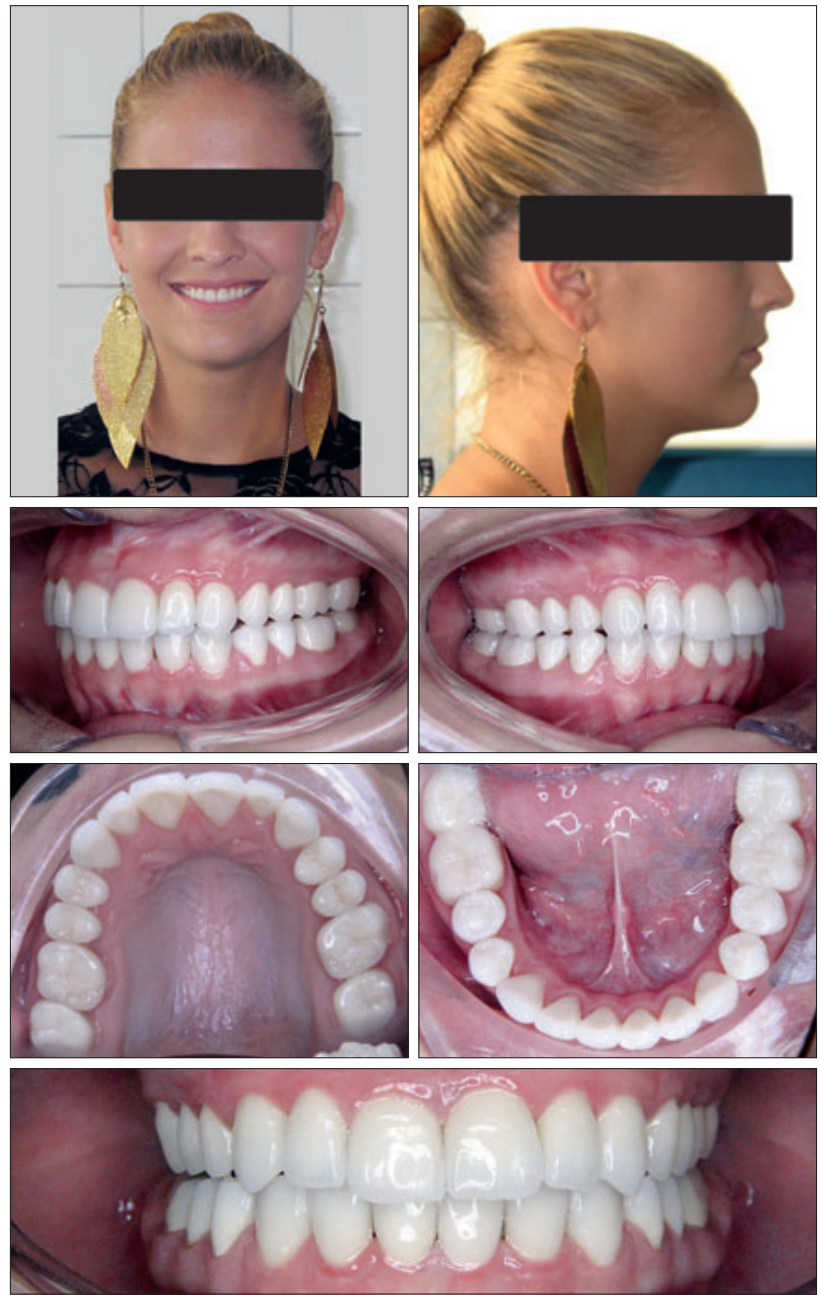

Fig. 9. Definitive reconstruction.

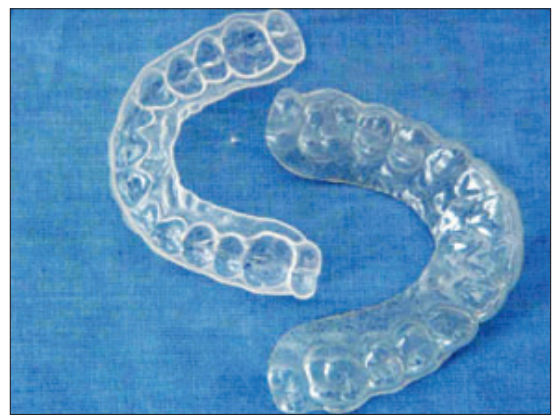

Fig. 10. Foil retainers.

dibular joint to the permanently changed jaw-to-jaw position after the definitive prosthodontic treatment.

After the teeth preparation, the impressions were made (Figs 6 and 7) and the temporary bridges were fixed (Fig. 5) for a period of 6 months. The bridges assisted in retaining the teeth in the right position after the orthodontic treatment. For the definitive aesthetic restoration, solo metal-free zirconia crowns were placed (Figs 8 and 9).
As after each orthodontic treatment, the patient had to wear the retainers to hold her teeth in the right position. We used transparent vacuum-formed Essix retainers (Fig. 10).

Figures 11 and 12 compare the patient's condition before and after the treatment. Apart from the routine preventive dental care, the regular orthodontic follow-up visits were scheduled to take place every 6 months.

\section{Discussion}

According to literature survey, most articles describe various case reports of AI and its treatment. The most frequently described conditions are in association with failure of permanent teeth eruption, changes in crown morphology and decreased amount of teeth (10). Hoppenreijs et al (8) compare skeletal components in AI and non-AI groups and have reported a higher incidence of reduced transversal width of dental arches in the former group. Similarly, our patient shows also a mild compression of the maxillary dental arch. Teeth with spacing in the anterior region and tight contact in the posterior regions are described in numerous articles (8). A similar situation is illustrated in our case study.
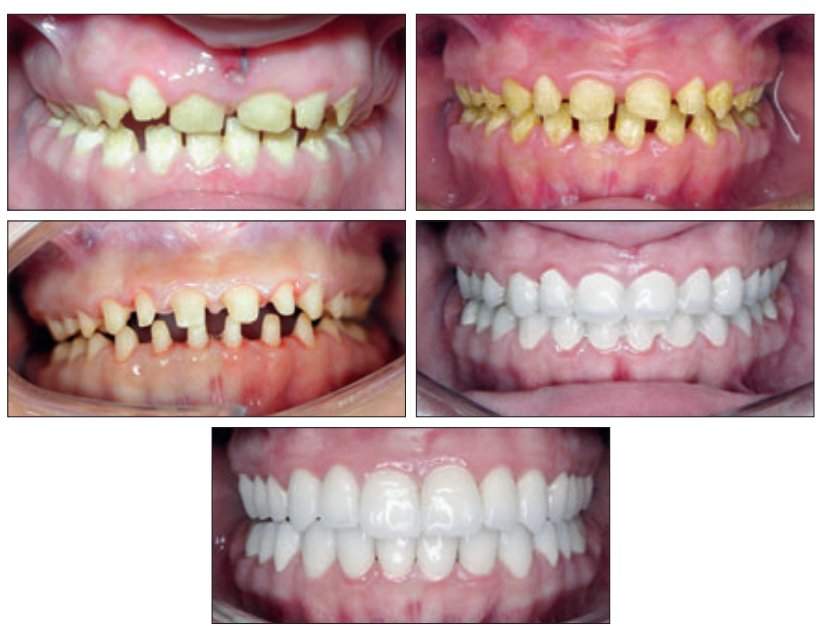

Fig. 11. Treatment history.

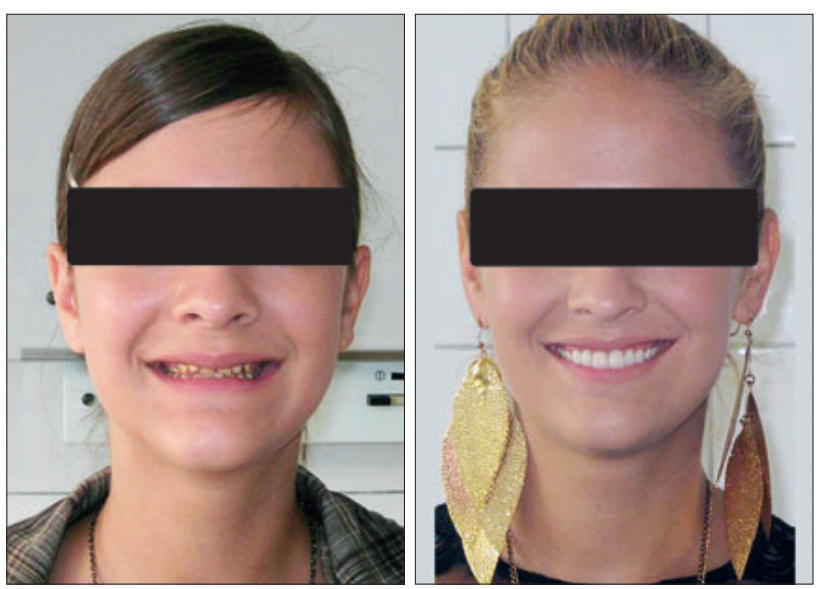

Fig. 12. Patient's appearance before and after the treatment. 
Rowly et al (4) reported increased lower facial height in association with anterior open bite in $24 \%$ of the patients with AI.

In their study, Koyuturuk et al (5) concluded that the enamel affected by AI shows significantly lower bond strength to materials that are usually used for fixation of orthodontic appliances. The enamel adhesiveness could be increased by pre-treating the teeth surface with $5 \%$ natriumhypochloride $(5,6,7)$.

\section{Conclusion}

This clinical report describes functional and aesthetic aspects of therapy in a patient suffering from hypoplastic AI. The therapy was based on a combination of orthodontic and prosthodontic treatments. It shows that early diagnosis and treatment focused on permanent aesthetic improvement in patients' appearance and correct function of jaw have a significant psychological impact on their future life.

This article shows that a carefully prepared treatment plan, good cooperation with the patient, and coordinated management of orthodontic and prosthodontic teamwork can bring excellent results and fulfil the patient's expectations.

\section{References}

1. Seow WK. Dental development in amelogenesis imperfecta: a controlled study. Pediatr Dent 1995; 17: 26-30.

2. Seymen F, Kiziltan B. Amelogenesis imperfecta: a scanning electron microscopic and histopathologic study. J Clin Pediatr Dent 2002; 26: $327-335$.

3. Atasu M, Biren S, Mumcu G. Hypocalcification type amelogenesis imperfecta in permanent dentition in association with heavily worn primary teeth, gingival hyperplasia, hypodontia and impacted teeth. J Clin Pediatr Dent 1999; 23: 117-121.

4. Rowley R, Hill FJ, Winter GB. An investigation of the association between anterior open-bite and amelogenesis imperfecta. Am J Orthod 1982; 81: 229-235.

5. Koyutürk AE, Kusgöz A, Sengün A, Ülker M, Sener Y. Micro-shear bond strength of two total-etching adhesives to enamel affected by amelogenesis imperfect. Dis Hekimligi Bilimleri Dergisi 2006; 12: 77-82.

6. Saroglu I, Aras S, Oztaş D. Effect of deproteinization on composite bond strength in hypocalcified amelogenesis imperfecta. Oral Dis 2006; 12: $305-308$.
7. Venezie RD, Vadiakas G, Christensen JR, Wright JT. Enamel pretreatment with sodium hypochlorite to enhance bonding in hypocalcified amelogenesis imperfecta: case report and SEM analysis. Pediatr Dent 1994; 16: 433-436.

8. Hoppenreijs TJ, Voorsmit RA, Freihofer HP. Open bite deformity in amelogenesis imperfecta. Part 1: An analysis of contributory factors and implications for treatment. J Craniomaxillofac Surg 1998; 26: 260-266.

9. Sanchez-Quevedo MC, Ceballos G, Garcia JM et al. Dentine structure and mineralization in hipocalcified amelogenesis imperfecta:a quantitative x-ray histochemical study. Oral Dis 2004; 10: 94-98.

10. Aren G, Ozdemir D, Firatli S, Uygur C, Sepet E, Firatli E. Evaluation of oral and systemic manifestations in an amelogenesis imperfecta population. J Dent 2003; 31: 585-591.

11. Cecetkova A.Vývojové poruchy tvrdých zubných tkanív. Stomato$\log , 3,2008$.

12. Aldred MJ, Crawford PJM, Savarirayan R. Amelogenesis imperfecta - a classification and catalogue for the 21st century. Oral Dis 2003; 9: 19-23.

13. Hart PS, Hart TC, Simmer JP, Wright JT. A nomenclature for Xlinked amelogenesis imperfecta. Arch Oral Biol 2002; 47: 255-260.

14. Iwasaki K, Bajenova E, Somogyi-Ganss E, Miller M, Nguyen V, Nourkeyhani H et al. Amelotin - a Novel Secreted, Ameloblast-specific Protein. J Dent Res 2005; 84: 1127-1132.

15. Gibson CW, Yuan ZA, Hall B, Longenecker G, Chen E, Thyagarajan T, Sreenath et al. Amelogenin-deficient mice display an amelogenesis imperfecta phenotype. J Biol Chem 2001; 276: 31871-31875.

16. Gisler V, Enkling N, Zix J, Kim K, Kellerhoff NM, Mericske-Stern R. A multidisciplinary approach to the functional and esthetic rehabilitation of amelogenesis imperfecta and open bite deformity: a case report. J Esthet Restor Dent 2010; 22 (5): 282-293.

17. Toksavul S, Ulusoy M, Türkün M, Kümbüloğlu O. Amelogenesis imperfecta: the multidisciplinary approach. A case report. Quintessence Int 2004; 35 (1): 11-14.

18. Varela Morales M, Botella Perez JM, Jiménez Garcia J, Varela PG. Interdisciplinary treatment of a patient with amelogenesis imperfecta. J Clin Orthod 2010; 44 (9): 553-559; quiz 562.

19. Sari T, Usumez A. Restoring function and esthetics in a patient with amelogenesis imperfecta: a clinical report. Prosthet Dent 2003; 90: 522-525.

20. Sengün A, Özer F. Restoring function and esthetics in a patient with amelogenesis imperfecta: a case report. Quintessence Int 2002; 33: 199-204.

Received February 11, 2012. Accepted April 13, 2012. 